\title{
PAPP-A2 deficiency does not exacerbate the phenotype of a mouse model of intrauterine growth restriction
}

\author{
Julian K. Christians * D, Kendra I. Lennie, Maria F. Huicochea Munoz and Nimrat Binning
}

\begin{abstract}
Background: Pregnancy-associated plasma protein-A2 (PAPP-A2) is consistently upregulated in the placentae of pregnancies complicated by preeclampsia and fetal growth restriction. The causes and significance of this upregulation remain unknown, but it has been hypothesized that it is a compensatory response to improve placental growth and development. We predicted that, if the upregulation of PAPP-A2 in pregnancy complications reflects a compensatory response, then deletion of Pappa2 in mice would exacerbate the effects of a gene deletion previously reported to impair placental development: deficiency of matrix metalloproteinase-9 (MMP9).
\end{abstract}

Methods: We crossed mice carrying deletions in Pappa2 and Mmp9 to produce pregnancies deficient in one, both, or neither of these genes. We measured pregnancy rates, number of conceptuses, fetal and placental growth, and the histological structure of the placenta.

Results: We found no evidence of reduced fertility, increased pregnancy loss, or increased fetal demise in $\mathrm{Mmp9}^{-/-}$ females. In pregnancies segregating for $\mathrm{Mmp9}, \mathrm{Mmp}^{-/-}$fetuses were lighter than their siblings with a functional Mmp9 allele. However, deletion of Pappa2 did not exacerbate or reveal any effects of Mmp9 deficiency. We observed some effects of Pappa2 deletion on placental structure that were independent of Mmp9 deficiency, but no effects on fetal growth. At G16, male fetuses were heavier than female fetuses and had heavier placentae with larger junctional zones and smaller labyrinths.

Conclusions: Effects of Mmp9 deficiency were not exacerbated by the deletion of Pappa2. Our results do not provide evidence that upregulation of placental PAPP-A2 represents a mechanism to compensate for impaired fetal growth.

Keywords: Placenta, Pregnancy, Preeclampsia, Intrauterine growth restriction, Pregnancy associated plasma protein, Matrix metalloproteinase, Insulin-like growth factor

\section{Background}

Intrauterine growth restriction and preeclampsia threaten the health and wellbeing of both the fetus and the mother, affecting $5-7 \%$ of pregnancies and constituting leading causes of perinatal and maternal mortality [1]. These conditions are thought to be caused, at least in part, by abnormal placental development and function [2]. There have been enormous efforts to identify the molecular mechanisms responsible for placental dysfunction in preeclampsia and intrauterine growth restriction, with numerous studies examining placental gene

\footnotetext{
* Correspondence: julian_christians@sfu.ca

Department of Biological Sciences, Simon Fraser University, Burnaby, BC, Canada
}

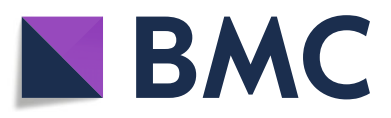

(๑) The Author(s). 2018 Open Access This article is distributed under the terms of the Creative Commons Attribution 4.0 International License (http://creativecommons.org/licenses/by/4.0/), which permits unrestricted use, distribution, and reproduction in any medium, provided you give appropriate credit to the original author(s) and the source, provide a link to the Creative Commons license, and indicate if changes were made. The Creative Commons Public Domain Dedication waiver (http://creativecommons.org/publicdomain/zero/1.0/) applies to the data made available in this article, unless otherwise stated. expression at delivery. Pregnancy-associated plasma protein-A2 (PAPP-A2) is one of the genes most consistently found to be upregulated in preeclampsia [3-7] and is also associated with fetal growth restriction [8]. Furthermore, elevated levels of PAPP-A2 in the maternal circulation in the first trimester have also been associated with preeclampsia $[9,10]$. PAPP-A2 is a protease of insulin-like growth factor binding protein 5 (IGFBP-5) [11] and is thought to regulate insulin-like growth factor (IGF) availability, although it may also function through other pathways [12]. IGFs play key roles in placental development [13], and their availability is regulated by six IGF binding proteins (IGFBPs). IGFs are released primarily through cleavage of the IGFBPs by proteases [14]. 
PAPP-A2 deficiency would therefore be expected to reduce IGF availability, and indeed loss-of-function mutations in humans reduce stature [15] while Pappa2 deletion in mice reduces body size [16-18] and increases IGFBP-5 levels [19].

Despite the high expression of PAPP-A2 in mouse placenta [20], Pappa2 deletion has no effect on pregnancy outcomes, apart from slightly reduced birthweight, which may be due to deletion in the fetus itself $[16,21]$. We therefore hypothesized that the upregulation of PAPP-A2 in human pregnancy complications represents a compensatory response to increase IGF signaling to promote placental growth and development [10, 22, 23]. To test this hypothesis, we deleted Pappa 2 in a mouse model of preeclampsia and intrauterine growth restriction: deficiency of matrix metalloproteinase-9 (MMP9) [24]. We selected this model since $M m p 9$ deletion impairs early placental development [24], and thus reflects "canonical" preeclampsia, rather than preeclampsia of other etiologies [25]. Deficiencies in early placental development would be expected to be ameliorated by increased IGF availability and, therefore, by increased PAPP-A2 expression. We predicted that, if the elevated expression of PAPP-A2 in preeclampsia in humans reflects a compensatory response, then deletion of Pappa 2 in mice would exacerbate effects of $M m p 9$ deletion, i.e., mice null for both Pappa 2 and $M m p 9$ would show a more severe phenotype than mice null for $M m p 9$ only. We focused on the number and size of fetuses, as well as placental histology since these were traits expected to be affected by Mmp 9 deficiency [24] and potentially ameliorated by PAPP-A2 and increased IGF availability.

\section{Methods}

All work was carried out in accordance with the guidelines of the Canadian Council on Animal Care and approved by the SFU University Animal Care Committee (protocol 1188B). Pappa 2 deletion mice with a C57BL/6 background were generated as previously described [16, 19]. Females homozygous for Pappa2 deletion (Pappa $2^{-/-}$) were crossed with a male homozygous for $M m p 9$ deletion $\left(M m p 9^{-/-}\right)$obtained from the Jackson Laboratory (stock number 007084) to produce offspring heterozygous at both genes. The first generation (F1) offspring were crossed to produce an F2 population that included mice with all nine possible genotypes (three $M m p 9$ genotypes x three Pappa2 genotypes). Females and males from the F2 population were selected based on Mmp 9 and Pappa2 genotype for breeding experiments, and were mated as described in Table 1 . Rather than using only homozygous mice, we performed a variety of crosses to make use of as many mice as possible (Table 1). Furthermore, mating type 1 with $M m p 9^{+/-}$males was previously reported to show a reduction in litter size and placental abnormalities
Table $1 \mathrm{Mmp} 9$ crosses performed in experiments

\begin{tabular}{lll}
\hline Mating type & Female MMP9 genotype & Male MMP9 genotype \\
\hline 0 & $-/-$ & $-/-$ \\
1 & $-/-$ & $+/-$ \\
2 & $+/-$ & $-/-$ \\
3 & $+/-$ & $+/-$ \\
4 & $+/+$ & $+/+$ \\
\hline
\end{tabular}

Each type of Mmp9 cross included either no functional Pappa2 alleles (Pappa $^{-/-} \times$Pappa2 $^{-/-}$) or at least one functional Pappa2 (achieved with various combinations of female and male genotype)

[24]. Beginning at approximately 8 weeks of age, females were placed with a male for one night, checked for vaginal plugs, and removed from the male whether or not a plug was observed. If no vaginal plug was observed and/or if female weight had not increased by $\sim 1 \mathrm{~g} 1$ week after mating, females were paired again. F2 females were collected at day 16 of gestation (G16; where the day after mating = day 0). To obtain mice for a further cohort, some females heterozygous at both genes $\left(\mathrm{Mmp}^{{ }^{+/-}}\right.$; Pappa $\left.2^{+/-}\right)$were paired with males homozygous for both deletions $\left(\mathrm{Mmp9}^{-/-} ; \mathrm{Pappa2}^{-/-}\right)$and not collected during pregnancy. We produced a backcross $(\mathrm{BC})$ population, rather than crossing heterozygotes, to increase the number of mice homozygous for $M m p 9$ and/or Pappa2 deletion. Females and males from the $\mathrm{BC}$ population were mated in the same manner as the F2 population, except that females were collected at day 18 of gestation (G18). Pregnancies were sampled at G18 in case effects were apparent only after G16. 63 F2 females were mated, yielding 43 G16 pregnancies (although one was mistakenly not collected during pregnancy) whereas $24 \mathrm{BC}$ females were mated, yielding $20 \mathrm{G} 18$ pregnancies.

At collection, females were blood sampled by cardiac puncture and the entire uterus was placed in $4 \%$ formaldehyde solution in phosphate buffered saline for 3 days before it was dissected to count and weigh individual fetuses and placentae, and to count putative fetal resorptions (green or green/brown masses). Maternal serum vascular endothelial growth factor (VEGF) was measured by enzyme-linked immunosorbent assay (R\&D Systems, MMV00). Fixed placentae were stored in $70 \%$ ethanol until embedded in paraffin. A subset of placentae were selected for sectioning, attempting to include one male and one female placenta for each female, and excluding heterozygous genotypes. Because previous work reported that both embryonic and maternal Mmp 9 deficiency affect placental development [24], we selected $M m p 9^{-/-}$ placentae from both $M m p 9^{-/-}$and $M m p 9^{+/-}$dams, as well as $M m p 9^{+/+}$placentae from $M m p 9^{+/+}$dams. For each placenta, multiple sections $(6 \mu \mathrm{m})$ were obtained $440 \mu \mathrm{m}$ apart, up to a maximum of 10 sections per placenta. Sections were stained with haematoxylin and eosin and the areas of the labyrinth, junctional zone and 
decidua were measured using ImageJ 1.48v. Damaged sections, and sections close to the edge of the placenta (i.e., where the labyrinth was mostly surrounded by junctional zone) were excluded, yielding 454 sections from 62 placentae (average: 7.3 sections per placenta). To obtain a single value for each of the labyrinth, junctional zone and decidua for each placenta, we analysed the areas from all 454 sections using a general linear model (proc GLM, SAS, Version 9.4) including terms for placenta identity and section location (i.e., close to the centre vs. further from the centre; sections further from the centre had smaller areas). From this analysis, we obtained the least squares mean for each placenta for each of the labyrinth, junctional zone and decidua.

To obtain tissue for genotyping, mice were ear-clipped at weaning or a small section of fetal tail was collected. Pappa2 genotype [19] and fetal sex [26] were determined as previously described. $M m p 9$ genotype was determined by PCR as recommended by the Jackson Laboratory (primers used: 5'-CTGAATGAACTGCA GGACGA-3'; 5'-ATACTTTCTCGGCAGGAGCA-3'; 5'-GTGGGACCATCATAACATCACA-3'; 5'-CTCG CGGCAAGTCTTCAGAGTA-3';).

All statistical analyses were performed using general linear models (proc GLM) or repeated measures analyses (proc MIXED) in SAS, Version 9.4 (SAS Institute Inc., Cary, NC). Repeated measures analyses (with dam as a random factor) were used for placental and fetal traits where there were multiple offspring per dam, since the dam was the unit of replication.

\section{Results}

The genotype ratios and postnatal growth of the F2 and $\mathrm{BC}$ populations are presented in the Additional file 1. Combining F2 and BC females, we found no evidence of reduced fertility or increased pregnancy loss in $M m p 9^{-/-}$ females. The proportion of females that became pregnant did not differ between $M m p 9^{-/-}$females and other females, whether all females were analysed together (Fisher's Exact Test $P=0.47$ ) or separately based on whether at least one wild-type Pappa2 allele was present (Fisher's Exact Test $P=1.00$ ) or not (Fisher's Exact Test $P=0.27$ ) (Table 2). Similarly, the proportion of females that had at least one failed mating (i.e., a vaginal plug was detected following mating, but pregnancy did not develop) did not differ between $M m p 9^{-/-}$females and other females. This was true whether all females were analysed together (Fisher's Exact Test $P=0.47$ ) or separately based on whether at least one wild-type Pappa 2 allele was present (Fisher's Exact Test $P=0.33$ ) or not (Fisher's Exact Test $P=1.00$ ) (Table 2). The number of times a female was paired with a male before becoming pregnant did not differ between $M m p 9^{-/-}$and other females $\left(F_{1,59}=0.18 ; P=0.67\right)$, and was not affected by whether at least one wild-type Pappa2 allele was present $\left(F_{1,59}=2.22 ; P=0.14\right)$, or by the interaction between these two factors $\left(F_{1,59}=0.10 ; P=0.76\right)$ (Table 2). Since the number of times a female was paired with a male varied only from 1 to 6 , we also analysed these data using a non-parametric Wilcoxon test. Again there was no difference between $M m p 9^{-/-}$and other females $(P=$ 0.71 ), pooling matings with and without at least one wild-type Pappa 2 allele present.

We also found no evidence of reduced fecundity or increased fetal loss in $\mathrm{Mmp9}^{-/-}$females. Including females collected at either G16 or G18, the number of fetuses did not differ between $M m p 9^{-/-}$and other females $\left(F_{1,58}=0.28 ; P=0.60\right)$, and was not affected by whether at least one wild-type Pappa2 allele was present $\left(\mathrm{F}_{1,58}=\right.$ $0.00 ; P=0.99)$ or the interaction between these two factors $\left(\mathrm{F}_{1,58}=0.17 ; P=0.68\right)$ (Fig. 1$)$. The number of putative embryo resorptions ranged from 0 to 4 , and tended to be slightly lower in $M m p 9^{-/-}$females (mean $=0.6$ ) than in other females (mean $=0.9$; Wilcoxon test $P=$ $0.25)$. The proportion of females that had at least one resorption did not differ between $M m p 9$ genotypes (11/30 $M m p 9^{-/-}$females vs. 16/32 other females; Fisher's Exact Test $P=0.32$ ).

At G16, the average fetal mass and average placental mass did not differ between $M m p 9^{-/-}$and other females,

Table 2 Effects of Mmp9 and Pappa2 deletion on fertility including F2 and BC females, i.e., females collected at G16 or G18

\begin{tabular}{|c|c|c|c|c|}
\hline & \multicolumn{2}{|c|}{$\begin{array}{l}\text { No wild-type Pappa2 alleles } \\
\text { Mmp9 mating type }\end{array}$} & \multicolumn{2}{|c|}{$\begin{array}{l}\text { At least one wild-type Pappa2 allele } \\
\text { Mmp9 mating type }\end{array}$} \\
\hline & $0-1$ & $2-4$ & $0-1$ & $2-4$ \\
\hline \# matings for pregnancy ${ }^{a}$ & $2.3 \pm 0.4$ & $2.3 \pm 0.3$ & $2.7 \pm 0.3$ & $2.9 \pm 0.3$ \\
\hline \# females that became pregnant & 11 & 16 & 19 & 17 \\
\hline \# females that did not become pregnant & 2 & 9 & 7 & 6 \\
\hline \# females with no failed matings ${ }^{b}$ & 9 & 18 & 18 & 19 \\
\hline \# females with failed mating ${ }^{\mathrm{b}}$ & 4 & 7 & 8 & 4 \\
\hline
\end{tabular}

a Least-squares means \pm standard error from a general linear model including Mmp9 mating type, whether mating had any wild-type Pappa2 alleles, and the interaction between these two terms

${ }^{\mathrm{b}} \mathrm{A}$ failed mating was defined as when a vaginal plug was detected following mating, but pregnancy did not develop; this analysis includes females that subsequently became pregnant, and those that never became pregnant 


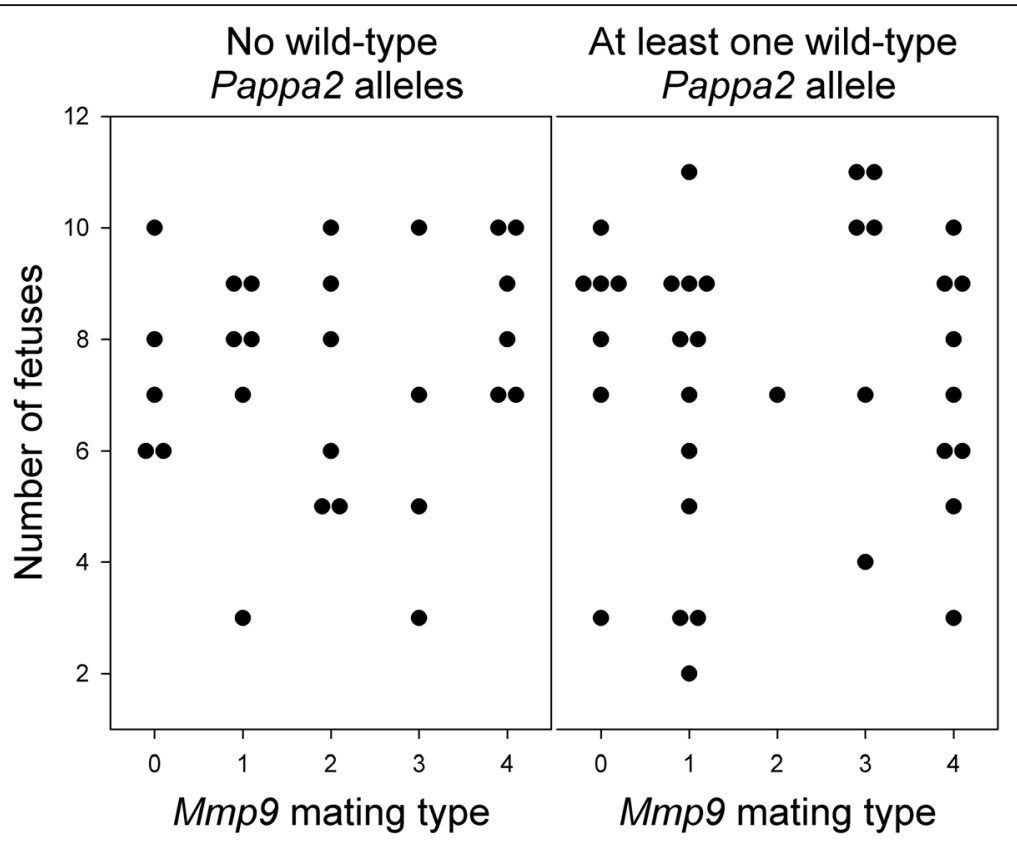

Fig. 1 Effect of Mmp9 and Pappa2 deletion on the number of fetuses, including females collected at either G16 or G18

and was not affected by whether at least one wild-type Pappa 2 allele was present or the interaction between these two factors (controlling for the number of fetuses, which was negatively related to fetal and placental mass; Table 3). There was no excess of very small or runted pups in $M m p 9^{-/-}$pregnancies (Fig. 2). There was a tendency for $M m p 9^{-/-}$females to have heavier placentae, but this was marginally non-significant $(P=0.07$, Table 3$)$. Considering only pregnancies with both $M m p 9^{+/-}$and $M m p 9^{-/-} \mathrm{fe}-$ tuses, $M m p 9^{-/-}$fetuses and their placentae were significantly lighter than their $M m p 9^{+/-}$siblings, but there was no effect of whether a wild-type Pappa2 allele was present in the pregnancy, and no interaction between $M m p 9$ and Pappa 2 (Table 4; Fig. 3). Male fetuses were heavier than female fetuses and had heavier placentae. The number of $M m p 9^{-/-}$to $\mathrm{Mmp}^{+/-}$conceptuses did not differ from the expected 1:1 ratio $\left(76 \mathrm{Mmp}^{-/-}\right.$vs. $73 \mathrm{Mmp}^{+/-} ; \mathrm{x}_{1}^{2}=$ $0.06 ; P=0.81$ ).

We also studied fetuses at G18, in case growth restriction was more apparent later in pregnancy. As at G16, the average fetal mass and average placental mass did not differ between $M m p 9^{-/-}$and other females, and was not affected by whether at least one wild-type Pappa2 allele was present or the interaction between these two factors, controlling for the number of fetuses (Table 3; Fig. 2). Average fetal mass tended to be lighter in $M m p 9^{-1-}$ females but this was marginally non-significant $(P=0.08$, Table 3$)$. Considering only pregnancies segregating at $M m p 9, M m p 9^{-/-}$fetuses were lighter than their $M m p 9^{+/-}$and $M m p 9^{+/+}$siblings, but there was no effect of whether a wild-type Pappa2 allele was present in the pregnancy, and no interaction

Table 3 Effects of Mmp9 and Pappa2 deletion on average fetal mass and average placental mass

\begin{tabular}{|c|c|c|c|c|c|c|c|c|}
\hline & \multicolumn{8}{|c|}{ Term in model } \\
\hline & \multicolumn{2}{|c|}{$\overline{M m p 9}$} & \multicolumn{2}{|c|}{ Pappa2 } & \multicolumn{2}{|c|}{ Mmp9*Pappa2 interaction } & \multicolumn{2}{|c|}{ Number of fetuses } \\
\hline & $F_{1,36}$ & $P$ & $F_{1,36}$ & $P$ & $F_{1,36}$ & $P$ & $F_{1,36}$ & $P$ \\
\hline Average fetal mass & 0.89 & 0.35 & 0.44 & 0.51 & 0.04 & 0.84 & 6.51 & 0.02 \\
\hline Average placental mass & 3.50 & 0.07 & 0.82 & 0.37 & 0.01 & 0.94 & 10.76 & 0.002 \\
\hline \multicolumn{9}{|l|}{ G18 } \\
\hline & $F_{1,15}$ & $P$ & $F_{1,15}$ & $P$ & $F_{1,15}$ & $P$ & $F_{1,15}$ & $P$ \\
\hline Average fetal mass & 3.41 & 0.08 & 1.13 & 0.31 & 0.03 & 0.86 & 2.08 & 0.17 \\
\hline Average placental mass & 0.61 & 0.45 & 1.00 & 0.33 & 0.00 & 0.98 & 1.11 & 0.31 \\
\hline
\end{tabular}

Statistics are from general linear models including effects of $M m p 9$ deletion (mating types 0 and 1 compared with others), Pappa2 deletion (whether the cross included at least one functional Pappa 2 allele or not), the interaction between these two factors, and the number of fetuses as a covariate 


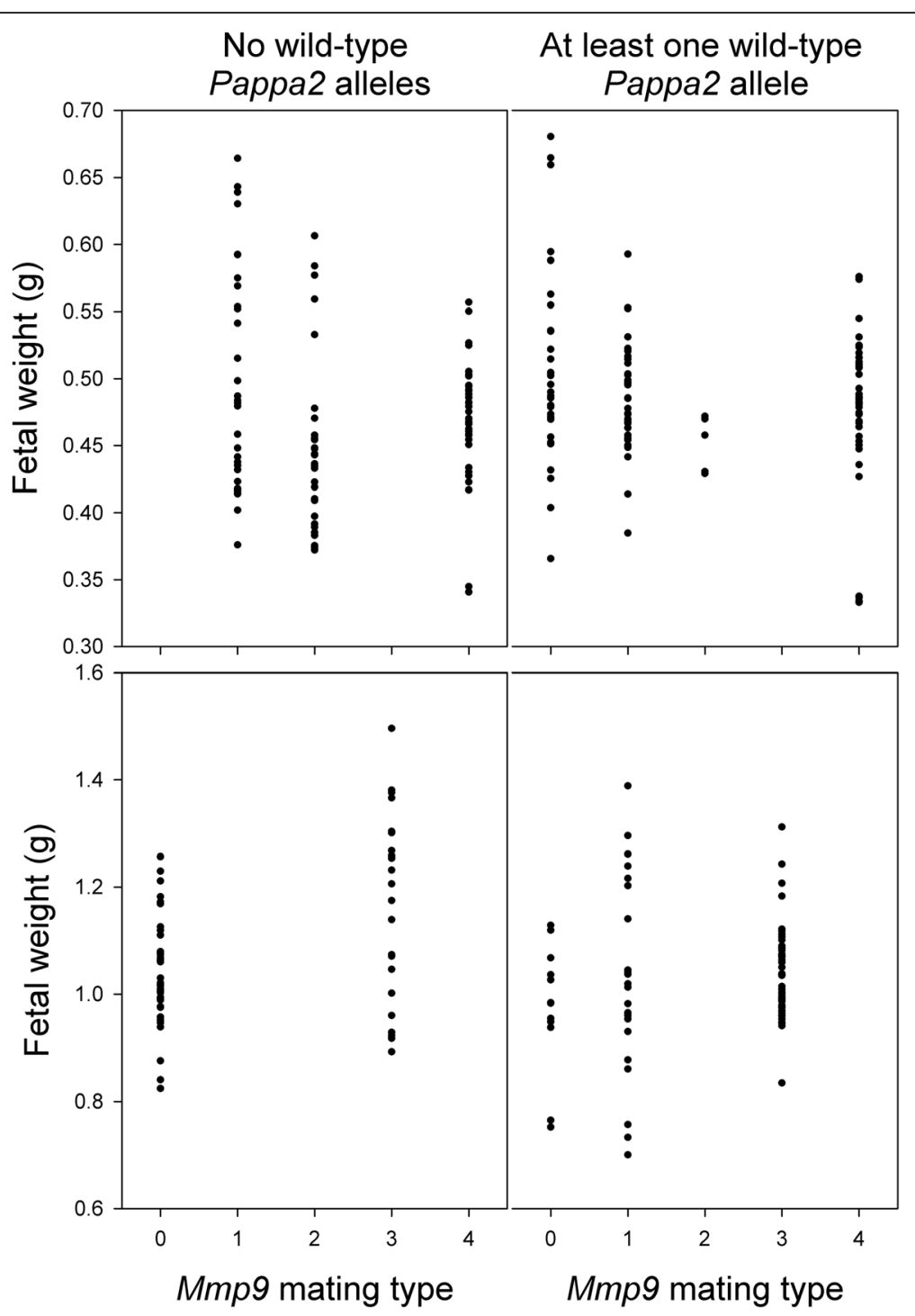

Fig. 2 Effect of Mmp9 and Pappa2 deletion on fetal weight at G16 (upper panels) and G18 (lower panels)

Table 4 Effects of Mmp9 and Pappa2 deletion on fetal mass and placental mass in pregnancies segregating for Mmp9

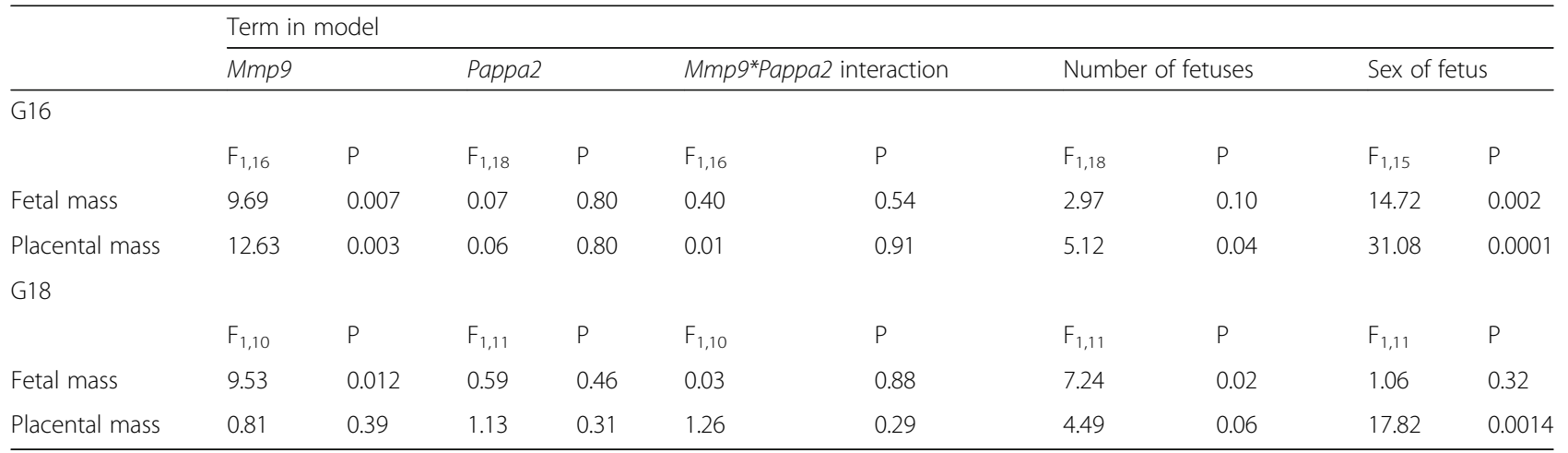

These analyses included multiple conceptuses per dam, and so statistics are from repeated measures analyses (with dam as a random factor), including effects of Mmp9 genotype of conceptus ( $\mathrm{Mmp9}^{-/-}$vs. $\mathrm{Mmp9}^{+/-}$and $\mathrm{Mmp9}^{+/+}$), Pappa2 deletion (whether the cross included at least one functional Pappa2 allele or not), the interaction between these two factors, fetal sex, and the number of fetuses as a covariate 


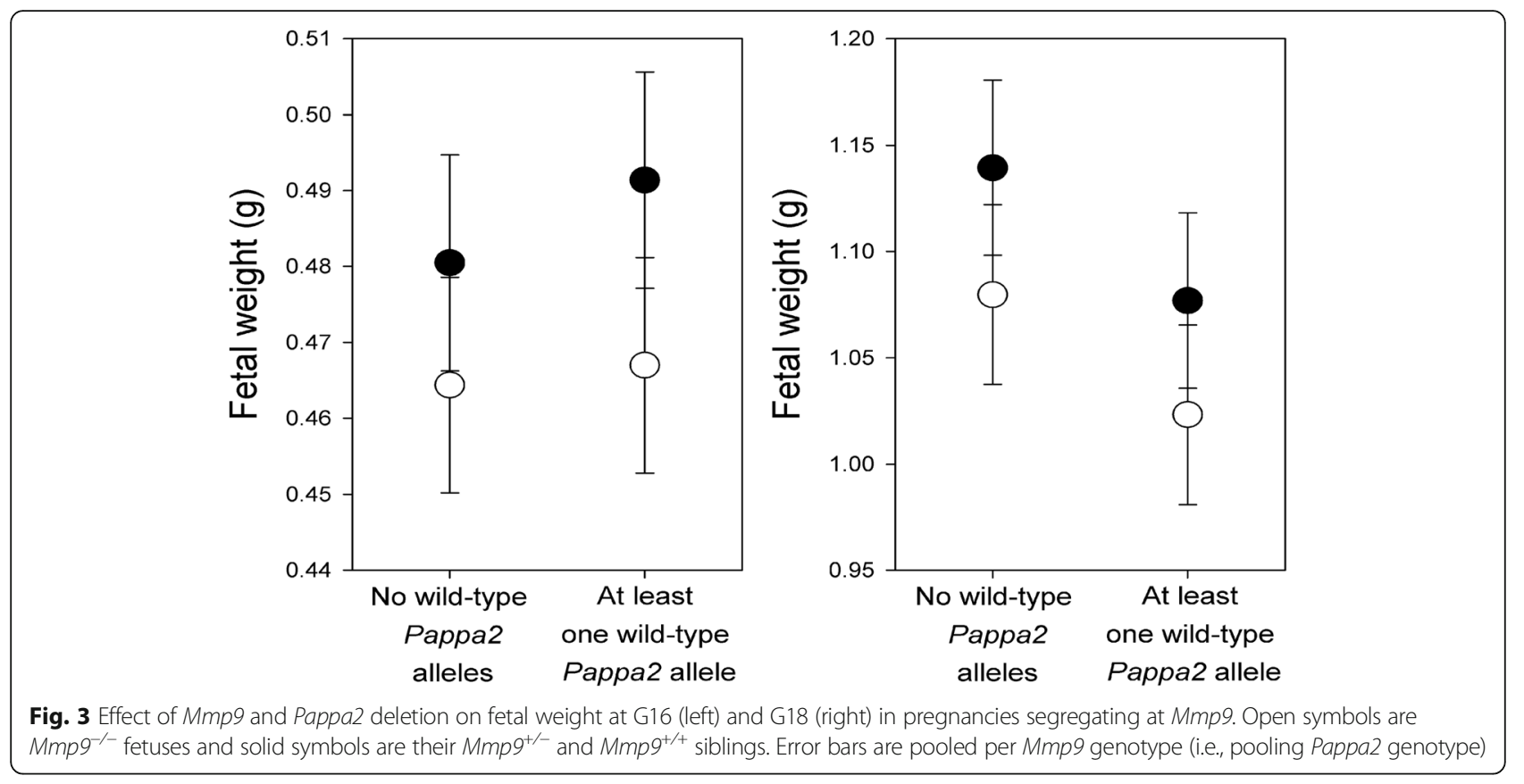

between Mmp9 and Pappa2 (Table 4; Fig. 3). There was no effect of $M m p 9$ genotype on placental weight. As at G16, male fetuses had heavier placentae than female fetuses. The genotype ratios did not differ from the expected Mendelian ratios in litters segregating for 2 genotypes $\left(16 \mathrm{Mmp}^{-/-}: 9 \mathrm{Mmp}^{+/-} ; \mathrm{x}^{2}{ }_{1}=1.96 ; \mathrm{P}=0.16\right)$ or three genotypes (26 Mmp $9^{-/-}: 40 \mathrm{Mmp}^{+/-}: 12$ $\left.M m p 9^{+/+} ; \mathrm{X}^{2}{ }_{1}=5.08 ; \mathrm{P}=0.08\right)$. Though non-significant, the trend was for an excess of $M m p 9^{-/-}$conceptuses.

At G16, we observed little effect of $M m p 9$ deficiency on the areas of the labyrinth, junctional zone or decidua, either in absolute terms or in terms of each component as a percentage of the total area (Table 5; Figs. 4 and 5). There was generally no interaction between $M m p 9$ deficiency and whether at least one wild-type Pappa2 allele was present (Table 5; Fig. 4), although $M m p 9^{-/-}$placentae from $M m p 9^{-/-}$dams with no Pappa2 had slightly smaller decidua area, when measured as a percentage of the total area (Table 5; Fig. 4). Pregnancies with no Pappa2 had smaller deciduas in absolute terms, and had larger labyrinths and smaller deciduas as a percentage of the total area, compared to pregnancies where at least one wild-type Pappa 2 allele was present (Table 5; Fig. 4). Placentae of male fetuses had larger junctional zone

Table 5 Effects of Mmp9 and Pappa2 deletion on the areas of the labyrinth, junctional zone and decidua, either in absolute terms, or as a percentage of total area

\begin{tabular}{|c|c|c|c|c|c|c|c|c|}
\hline & \multicolumn{8}{|c|}{ Term in model } \\
\hline & \multicolumn{2}{|c|}{$\overline{M m p 9^{a}}$} & \multicolumn{2}{|c|}{ Pappa2 } & \multicolumn{2}{|c|}{ Mmp9*Pappa2 interaction } & \multicolumn{2}{|c|}{ Sex of fetus } \\
\hline & $F_{2,28}$ & $P$ & $\overline{F_{1,28}}$ & $P$ & $\mathrm{~F}_{2,28}$ & $P$ & $\mathrm{~F}_{1,20}$ & $P$ \\
\hline \multicolumn{9}{|l|}{ Absolute } \\
\hline Labyrinth & 0.20 & 0.82 & 0.00 & 0.98 & 1.64 & 0.21 & 0.10 & 0.75 \\
\hline Junctional Zone & 0.38 & 0.69 & 1.93 & 0.18 & 0.69 & 0.51 & 14.76 & $0.001^{b}$ \\
\hline Decidua & 3.17 & 0.06 & 7.89 & 0.01 & 2.62 & 0.09 & 2.90 & 0.10 \\
\hline \multicolumn{9}{|l|}{ Percentage of total } \\
\hline Labyrinth & 1.15 & 0.33 & 6.89 & 0.01 & 1.80 & 0.18 & 15.01 & $0.001^{\mathrm{b}}$ \\
\hline Junctional Zone & 1.41 & 0.26 & 0.79 & 0.38 & 0.04 & 0.96 & 11.63 & $0.003^{b}$ \\
\hline Decidua & 4.10 & 0.03 & 6.97 & 0.01 & 3.96 & 0.03 & 0.00 & 0.98 \\
\hline
\end{tabular}

These analyses included multiple conceptuses per dam, and so statistics are from repeated measures analyses (with dam as a random factor), including effects of Mmp9 group, Pappa2 deletion (whether the cross included at least one functional Pappa2 allele or not), the interaction between these two factors, and fetal sex

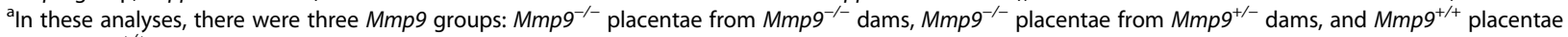
from $\mathrm{Mmp9}^{+/+}$dams

${ }^{\mathrm{b}}$ Area of the junctional zone, both absolute and as a percentage of the total area, was larger in males than females, while the area of the labyrinth as a percentage of the total was smaller in males 

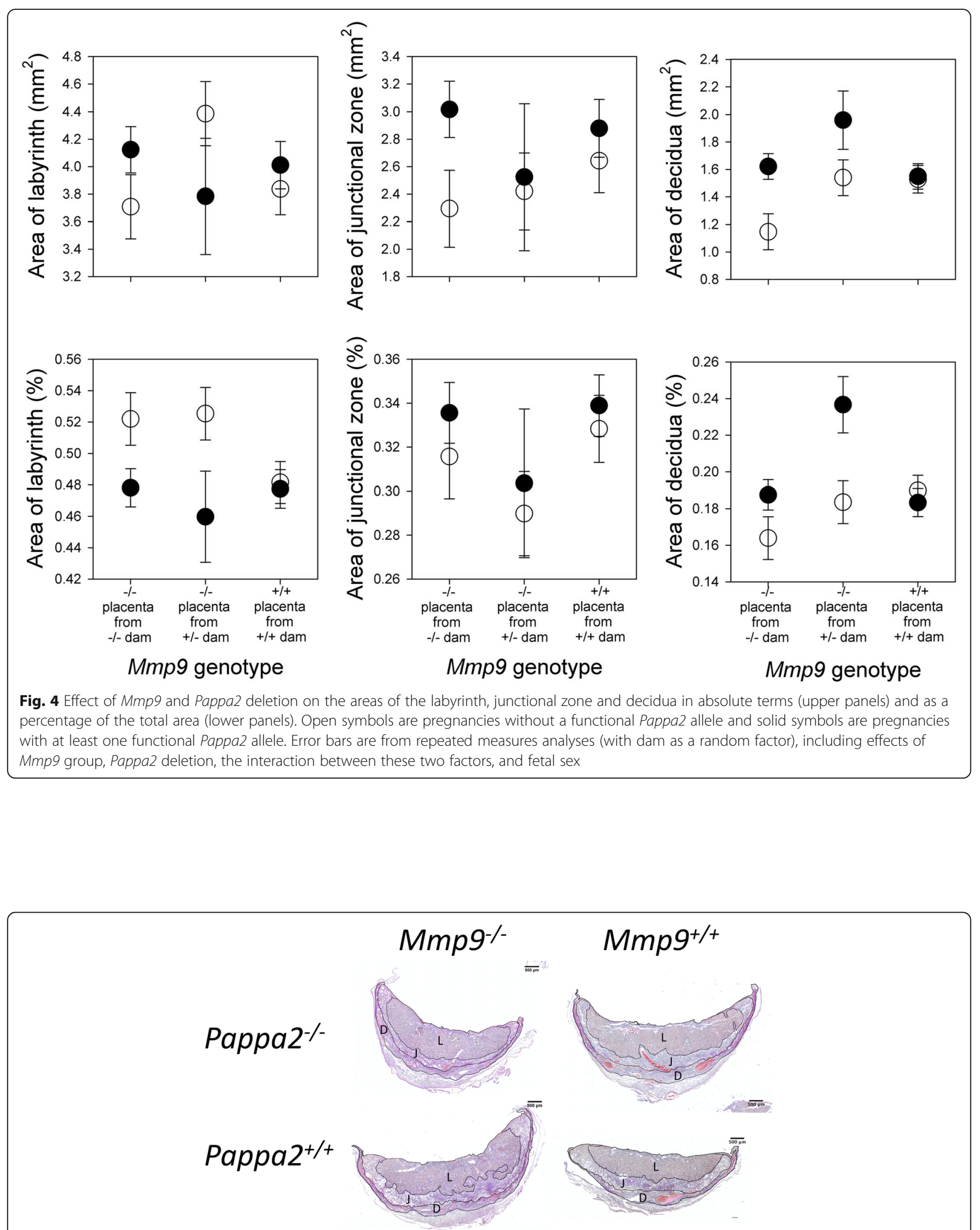

Fig. 5 Representative images of G16 placental sections from $\mathrm{Mmp}^{-/-}$placentae from $\mathrm{Mmp}^{-/ /}$dams and $\mathrm{Mmp}^{+/ /+}$placentae from $\mathrm{Mmp}^{+/+}$ dams, with and without Pappa2, showing the outlined labyrinth (L), junctional zone (J) and decidua (D). All placentae are from female fetuses 
areas in absolute terms and, as a percentage of the total area, had larger junctional zones and smaller labyrinths.

The previous report of $M m p 9$ deletion mice [24] described reduced serum VEGF levels in $\mathrm{Mmp}^{-/-} \mathrm{fe}-$ males. We analysed VEGF levels at G16 in a subset of pregnancies of $M m p 9^{-/-}$and $M m p 9^{+/+}$females, all with at least one wild-type Pappa2 allele. VEGF levels did not differ between $M m p 9^{-/-}$and $M m p 9^{+/+}$females $\left(\mathrm{F}_{1,10}=0.12 ; P=0.73\right)$, but were positively related with the number of conceptuses $\left(F_{1,10}=13.70 ; P=0.004\right.$; Fig. 6).

\section{Discussion}

In humans, placental PAPP-A2 is upregulated in preeclampsia [3-7] and fetal growth restriction [8]. However, deletion of Pappa2 in mice has little effect on pregnancy outcome [16, 21], suggesting that the upregulation of PAPP-A2 in human pregnancy complications may represent a compensatory response [10, 22, 23]. If PAPP-A2 is important in compensating for placental insufficiency, it would be expected that its absence would exacerbate the effects of placental dysfunction. Previously, Mmp9 deficiency has been reported to cause placental abnormalities resulting in growth restriction [24]. We observed that $M m p 9^{-/-}$fetuses were lighter than $M m p 9^{+/-}$siblings, but this difference was not exacerbated by deletion of Pappa2. Therefore, our results do not provide evidence that PAPP-A2 contributes to placental mechanisms that compensate for poor fetal growth.

Surprisingly, we found no effect of $M m p 9$ deletion, with or without deletion of Pappa2, on fertility, fecundity, pregnancy loss, fetal loss or placental structure. While the publication describing $M m p 9$ deletion as a model of preeclampsia and intrauterine growth

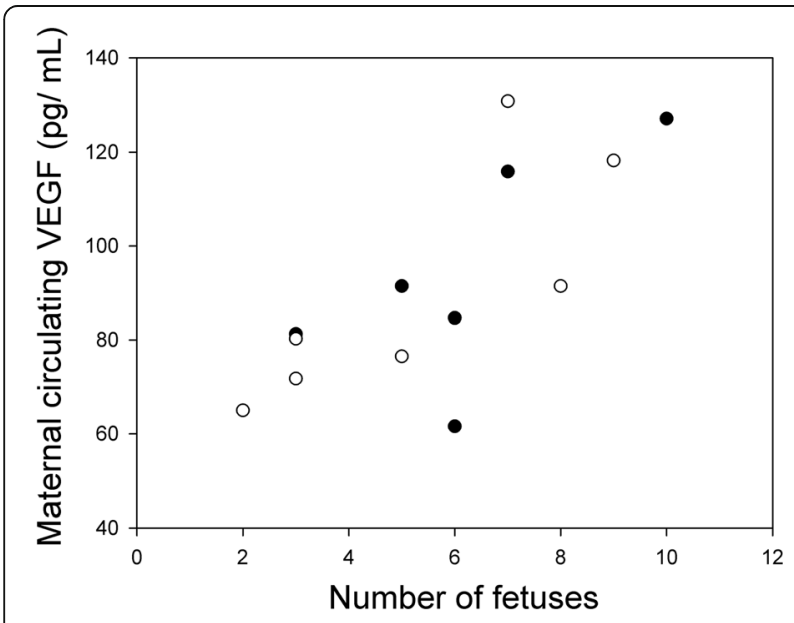

Fig. 6 Relationship between number of fetuses and VEGF levels in the maternal circulation of $\mathrm{Mmp9}^{-1-}$ dams (open symbols) and $\mathrm{Mmp9}^{+/+}$dams (solid symbols) at G16. All pregnancies have at least one functional copy of Pappa2 restriction reported "as much as a 50\% reduction in litter size" [24], no data were presented, and the original report of $M m p 9$ deletion described a much more modest reduction in litter size (1.6 pups) [27]. In our experiments, $M m p 9^{-/-}$females were compared with control siblings, and no experimental females were daughters of $M m p 9^{-/-}$females. It is therefore possible that by avoiding maternal effects of $M m p 9$ deletion, the severity of the deletion was reduced; whether previous reports $[24,27]$ used our breeding scheme is not clear.

The previous report of the effects of $M m p 9$ deficiency on pregnancy also reported reduced levels of VEGF in the maternal circulation [24]. VEGF influences placental angiogenesis, and maternal circulating VEGF levels are reduced in preeclamptic human pregnancies [28]. While there was no effect of $M m p 9$ deficiency on circulating maternal VEGF in the present study, we found a positive association between VEGF levels and the number of conceptuses. The previous report of reduced VEGF in $M m p 9^{-/-}$females [24] may therefore have been due to reduced numbers of conceptuses, rather than to placental pathology.

In addition to some modest effects of $M m p 9$ and Pappa2 deletion, we observed more robust differences between the sexes in fetal mass, placental mass, and placental structure at G16, as well as placental mass at G18. These differences may reflect sex-specific strategies for fetal growth and placental function [29] with potential long term effects on offspring health [30].

\section{Conclusions}

Previous work reported that deletion of $M m p 9$ reduced pregnancy rates and implantation success following embryo transfer, decreased litter size, and increased rates of fetal demise and growth restriction [24]. In contrast, we found only modest effects of $M m p 9$ deletion on fetal growth, and found no effects on the number of fetuses, the number of putative embryo resorptions, or female fertility (number of matings required to achieve pregnancy, the proportion of females that became pregnant, or the number of females with failed matings). The difference in results between our study and previous work may have been due to our experimental design, which compared $\mathrm{Mmp}^{-1}$ - females with control siblings and thus avoided confounding maternal effects. The effects of $M m p 9$ deficiency were not exacerbated by the deletion of Pappa2, and therefore our results do not support the hypothesis that PAPP-A2 upregulation in human pregnancy complications represents a compensatory response to ameliorate placental growth and development. Our results provide insight into the role of PAPP-A2 dysregulation in devastating pregnancy complications, which may inform the use of this protein as an early biomarker of placental health $[9,10]$. Our work also serves as a caution regarding the use of Mmp9 deficiency as a model of these complications. 


\section{Additional files}

Additional file 1: Genotype ratios and postnatal growth of F2 and BC populations. (DOCX $326 \mathrm{~kb}$ )

Additional file 2: Datasets analysed in this study. (XLSX 69 kb)

\section{Abbreviations}

BC: Backcross; F1: First generation; F2: Second generation; G16, G18: day 16 or 18 of gestation, where the day after mating = day 0; IGF: Insulin-like growth factor; IGFBP: Insulin-like growth factor binding protein; MMP9: Matrix metalloproteinase-9; PAPP-A2: Pregnancy-associated plasma protein-A2; VEGF: Vascular endothelial growth factor

\section{Acknowledgements}

We are grateful for assistance from Alex Fraser (training in histological techniques), Danielle Mara and Alex Beristain (imaging placental sections), Rajan Sidhu (measuring placental areas), Monika Rogowska (genotyping), and the Animal Care staff at Simon Fraser University (animal maintenance and timed matings). We thank two anonymous reviewers for constructive comments on the manuscript.

\section{Funding}

This study was funded by an NSERC (Canada) Discovery Grant to JKC, a Simon Fraser University Vice President, Research Undergraduate Student Research Award (USRA) to KIL, and an NSERC USRA to NB. The funding bodies had no role in study design, collection, analysis, and interpretation of data or in manuscript preparation.

\section{Availability of data and materials}

The dataset supporting the conclusions of this article is included as an additional file (Additional file 2).

\section{Authors' contributions}

JKC conceived of the study, contributed to laboratory work, carried out statistical analyses, and wrote the manuscript. KIL performed the laboratory work and helped draft the manuscript. NB contributed to laboratory work, analysed the placental images, and helped draft the manuscript. MFHM analysed the placental images and helped draft the manuscript. All authors approve and are accountable for the final version.

\section{Ethics approval}

All work was carried out in accordance with the guidelines of the Canadian Council on Animal Care and approved by the SFU University Animal Care Committee (protocol 1188B)

\section{Competing interests}

The authors declare that they have no competing interests.

\section{Publisher's Note}

Springer Nature remains neutral with regard to jurisdictional claims in published maps and institutional affiliations.

\section{Received: 13 April 2018 Accepted: 6 June 2018}

Published online: 12 June 2018

\section{References}

1. Huppertz B. Placental origins of preeclampsia - challenging the current hypothesis. Hypertension. 2008;51:970-5.

2. Pijnenborg R, Vercruysse L, Brosens I. Deep placentation. Best Pract Res Clin Obstet Gynaecol. 2011;25:273-85.

3. Vaiman D, Miralles F. An integrative analysis of preeclampsia based on the construction of an extended composite network featuring protein-protein physical interactions and transcriptional relationships. PLoS One. 2016;11: e0165849.

4. Brew O, Sullivan MHF, Woodman A. Comparison of normal and preeclamptic placental gene expression: a systematic review with metaanalysis. PLoS One. 2016;11:e0161504
5. Kleinrouweler $C E$, van Uitert M, Moerland PD, Ris-Stalpers C, van der Post JAM, Afink GB. Differentially expressed genes in the pre-Eclamptic placenta: a systematic review and meta-analysis. PLoS One. 2013;8:e68991.

6. Kramer AW, Lamale-Smith LM, Winn VD. Differential expression of human placental PAPP-A2 over gestation and in preeclampsia. Placenta. 2016;37:19-25.

7. Macintire K, Tuohey L, Ye L, Palmer K, Gantier M, Tong S, et al. PAPPA2 is increased in severe early onset pre-eclampsia and upregulated with hypoxia. Reprod Fertil Dev. 2014;26:351-7.

8. Whitehead CL, Walker SP, Ye L, Mendis S, Kaitu'u-Lino TJ, Lappas M, et al. Placental specific mRNA in the maternal circulation are globally dysregulated in pregnancies complicated by fetal growth restriction. J Clin Endocrinol Metab. 2013;98:E429-36.

9. Hansen YB, Myrhøj V, Jørgensen FS, Oxvig C, Sørensen S. First trimester PAPP-A2, PAPP-A and hCG $\beta$ in small-for-gestational-age pregnancies. Clin Chem Lab Med. 2016:54:117-23.

10. Crosley EJ, Durland U, Seethram K, Macrae S, Gruslin A, Christians JK. Firsttrimester levels of pregnancy-associated plasma protein A2 (PAPP-A2) in the maternal circulation are elevated in pregnancies that subsequently develop preeclampsia. Reprod Sci. 2014;21:754-60.

11. Overgaard MT, Boldt HB, Laursen LS, Sottrup-Jensen L, Conover CA, Oxvig C. Pregnancy-associated plasma protein-A2 (PAPP-A2), a novel insulin-like growth factor-binding protein-5 proteinase. J Biol Chem. 2001;276:21849-53.

12. Kjaer-Sorensen $K$, Engholm DH, Jepsen MR, Morch MG, Weyer K, Hefting LL, et al. Papp-a2 modulates development of cranial cartilage and angiogenesis in zebrafish embryos. J Cell Sci. 2014;127:5027-37.

13. Sferruzzi-Perri AN, Owens JA, Pringle KG, Roberts CT. The neglected role of insulin-like growth factors in the maternal circulation regulating fetal growth. J Physiol. 2011;589:7-20.

14. Bunn RC, Fowlkes JL. Insulin-like growth factor binding protein proteolysis. Trends Endocrinol Metab. 2003;14:176-81.

15. Dauber A, Munoz-Calvo MT, Barrios V, Domene HM, Kloverpris S, Serra-Juhe $C$, et al. Mutations in pregnancy-associated plasma protein A2 cause short stature due to low IGF-I availability. EMBO Mol Med [Internet]. 2016;8:36374. Available from: http://embomolmed.embopress.org/cgi/doi/10.15252/ emmm.201506106

16. Christians JK, de Zwaan DR, Fung SHY. Pregnancy associated plasma protein A2 (PAPP-A2) affects bone size and shape and contributes to natural variation in postnatal growth in mice. PLoS One. 2013;8:e56260.

17. Amiri N, Christians JK. PAPP-A2 expression by osteoblasts is required for normal postnatal growth in mice. Growth Hormon IGF Res. 2015;25: 274-80.

18. Conover CA, Boldt HB, Bale LK, Clifton KB, Grell JA, Mader JR, et al. Pregnancy-associated plasma protein-A2 (PAPP-A2): tissue expression and biological consequences of gene knockout in mice. Endocrinology. 2011; $152 \cdot 2837-44$

19. Christians JK, Bath AK, Amiri N. Pappa2 deletion alters IGFBPs but has little effect on glucose disposal or adiposity. Growth Hormon IGF Res. 2015;25: 232-9.

20. Wang J, Qiu Q, Haider M, Bell M, Gruslin A, Christians JK. Expression of pregnancy-associated plasma protein A2 during pregnancy in human and mouse. J Endocrinol. 2009:202:337-45.

21. Christians JK, King AY, Rogowska MD, Hessels SM. Pappa2 deletion in mice affects male but not female fertility. Reprod Biol Endocrinol. 2015:13:109.

22. Wagner PK, Otomo A, Christians JK. Regulation of pregnancy-associated plasma protein A2 (PAPPA2) in a human placental trophoblast cell line (BeWo). Reprod Biol Endocrinol. 2011;9:48.

23. Christians JK, Gruslin A. Altered levels of insulin-like growth factor binding protein proteases in preeclampsia and intrauterine growth restriction. Prenat Diag. 2010;30:815-20

24. Plaks V, Rinkenberger J, Dai J, Flannery M, Sund M, Kanasaki K, et al. Matrix metalloproteinase-9 deficiency phenocopies features of preeclampsia and intrauterine growth restriction. Proc Natl Acad Sci U S A. 2013;110:11109-14

25. Leavey K, Benton SJ, Grynspan D, Kingdom JC, Bainbridge SA, Cox BJ. Unsupervised placental gene expression profiling identifies clinically relevant subclasses of human preeclampsia. Hypertension. 2016:68: 137-47

26. McFarlane L, Truong V, Palmer JS, Wilhelm D. Novel PCR assay for determining the genetic sex of mice. Sex Dev. 2013;7:207-11.

27. Dubois B, Arnold B, Opdenakker G. Gelatinase B deficiency impairs reproduction. J Clin Invest. 2000;106:627-8. 
28. Andraweera PH, Dekker GA, Roberts $C T$. The vascular endothelial growth factor family in adverse pregnancy outcomes. Hum Reprod Update. 2012;18:436-57.

29. Clifton VL. Review: Sex and the human placenta: mediating differential strategies of fetal growth and survival. Placenta. 2010;31:S33-9.

30. Chin EH, Christians JK. When are sex-specific effects really sex-specific? J Dev Orig Health Dis. 2015;6:438-42.

Ready to submit your research? Choose BMC and benefit from:

- fast, convenient online submission

- thorough peer review by experienced researchers in your field

- rapid publication on acceptance

- support for research data, including large and complex data types

- gold Open Access which fosters wider collaboration and increased citations

- maximum visibility for your research: over $100 \mathrm{M}$ website views per year 